\title{
A PEDAGOGIA INDUSTRIAL DO EMPRESARIADO MINEIRO NO CONTEXTO DA CRISE POLÍTICA E ECONÔMICA E DO GOLPE MILITAR (1961-1964)
}

\author{
Jane Maria dos Santos Reis ${ }^{1}$ \\ Cinval Filho dos Reis ${ }^{2}$
}

\section{RESUMO}

Este artigo tem como objetivo problematizar os planos e estratégias dos processos formativos destinados aos trabalhadores da indústria mineira no contexto da crise política e econômica do Golpe Militar. Para isso, fez-se necessária a articulação do debate entre educação e trabalho sob a perspectiva do materialismo histórico dialético. Trata-se de discussão bibliográfica que tem como referência o pensamento empresarial expresso na concretude da formação dos trabalhadores da e para a indústria de Minas Gerais (Pedagogia Industrial), em consenso com as demandas de trabalho e de formação das empresas mineiras. Além disso, o debate estabelecido com a literatura relacionada foi articulado, por meio de análise documental, a um diálogo com as fontes primárias, oriundas da Revista Vida Industrial que trouxeram em seu bojo a lógica educacional representativa do empresariado industrial mineiro associado à FIEMG (Federação das Indústrias do Estado de Minas Gerais). Dessa forma, as ações empresariais que constituíram a Pedagogia Industrial, estavam articuladas às concepções políticas e econômicas do desenvolvimento no Brasil, visto que o disciplinamento para o trabalho imposto por tais concepções atendia à formação humana do trabalhador voltada para a acumulação do capital em geral e do capital industrial em específico - além de acarretar, contraditoriamente, as possibilidades de se construir a formação humana para além do capital.

Palavras-chave: Pedagogia Industrial. Revista Vida Industrial. Indústria. Empresariado Industrial. Golpe Militar.

\section{INDUSTRIAL ENTREPRENEURS OF PEDAGOGY MINER IN THE CONTEXT OF ECONOMIC CRISIS AND POLITICAL AND MILITARY COUP (1961-1964)}

\begin{abstract}
This article aims to discuss the plans and strategies of training processes for workers in the mining industry in the context of political and economic crisis of the military coup. For this, it was necessary to link the debate between education and work from the perspective of dialectical historical materialism. It is a bibliographic discussion that is referenced in the express business thinking concreteness training of workers and industry of Minas Gerais (Industrial Education), in agreement with the demands of work and training of mining companies. Moreover, the debate established with the related literature was articulated through documentary analysis, a dialogue with the primary sources, arising from the Industrial Life Magazine who brought with them the educational representative of the mining industrial business logic associated with FIEMG (Federation of Industries of the State of Minas Gerais). Thus, corporate actions which constituted the Industrial Pedagogy, were articulated to political and economic conceptions of development in Brazil, since the discipline to work imposed by these concepts met the human worker training geared to the accumulation of capital in general and industrial capital in particular - in addition to leading, paradoxically, the possibilities of building human capital training beyond.
\end{abstract}

Keywords: Industrial Education. Industrial Life Magazine. Industry. Industrial entrepreneurs. Military coup. 


\section{Introdução}

As mudanças políticas e econômicas ocorridas na sociedade brasileira desde as primeiras décadas do século XX, trazem consigo o fato de que o mundo do trabalho e o próprio trabalho em si, sofreu transformações, acarretadas principalmente pela constante reconfiguração da sua organização técnico-organizacional, mediante o processo de industrialização. Neste cenário, historicamente contextualizado entre o período de 1961 a 1964, pelas ações do Estado, do empresariado nacional, do empresariado estrangeiro e por diversas transformações no setor produtivo, os projetos e ações do empresariado industrial adquirem destaque no âmbito da educação, no que concerne ao processo formativo dos trabalhadores da indústria, haja vista que é notável a ênfase das entidades representativas dos interesses empresariais na reformulação do sistema educacional, objetivando uma economia desenvolvida. Assim, tem-se como objetivo problematizar os planos e estratégias dos processos formativos destinados aos trabalhadores da indústria mineira no contexto da crise política e econômica do Golpe Militar.

Essa perspectiva se efetiva historicamente a partir da consolidação cada vez mais consistente, dos principais órgãos representativos da burguesia industrial, dentre as quais se destaca, tanto em termos nacionais quanto em termos estaduais, a Federação das Indústrias do Estado de Minas Gerais (FIEMG). Essas instituições "personalizaram" o empresariado industrial brasileiro enquanto um dos principais protagonistas socioeconômicos de vários processos de mudanças continuamente em curso.

Essa reorganização da estrutura histórica e produtiva se expressa na educação, a partir de fatores determinantes para a construção e consolidação de projetos de formação humana a favor do capital, ou seja, numa Pedagogia Industria ${ }^{3}$, da fábrica e, consequentemente na formação de um trabalhador industrial alienado.

Nesse contexto, a educação na indústria, implica em pensar e repensar de forma contextualizada na sua respectiva demanda por um determinado perfil de trabalhador, que corresponde ao homem do seu tempo, que é submetido a uma formação que esteja histórica e economicamente em consonância com a realidade produtiva e organizacional do trabalho. Logo, enquanto a FIEMG é considerada a "porta-voz" da indústria mineira, a sua voz, propriamente dita, foi, por várias décadas, a Revista Vida Industrial e foi justamente ela que veiculou as representações do empresariado em relação à educação para a indústria. Por isso, foi fundamental recorrer às fontes primárias, em síntese expressas pela Revista Vida Industrial da FIEMG, por se tratar justamente da expressão consolidada das diferentes nuances do projeto de formação humana do empresariado industrial mineiro. Nesse sentido, a educação a serviço do capital e sob a representação do empresariado industrial, é concebida como chave para o desenvolvimento econômico.

Em termos metodológicos, foi desenvolvida uma pesquisa bibliográfica articulada à análise documental enquanto técnica imprescindível para o estudo das fontes primárias, que implicam em levantar documentos de natureza não mensurável, os quais foram estudados a fim de encontrar significados. Essa análise documental foi centrada nas matérias da Revista Vida Industrial que abordavam as representações e projetos educacionais do empresariado mineiro, que constituíram a Pedagogia Industrial.

A relevância deste trabalho se justifica pelo fato que a atuação do empresariado industrial mineiro foi primordial para a expansão industrial brasileira e para a consolidação do desenvolvimento dependente e associado - fato este que merece ser analisado de modo crítico e aprofundado.

Estabelecem-se, portanto, diferentes lógicas, do âmbito estatal, do âmbito político e do âmbito econômico, que vêm intensificar o processo de acumulação do capital, mas que 
ao mesmo tempo, carregam consigo, em suas contradições, as possibilidades de se construir a formação humana para além da Pedagogia Industrial e do capital.

\section{Os planos e estratégias educacionais do empresariado mineiro para os trabalhadores da indústria no contexto da crise e do Golpe Militar}

A história do ensino industrial brasileiro entre os anos de 1945 e 1964 trouxe marcos significativos, sendo alvo de inúmeros debates em âmbito nacional e também sofrendo várias modificações. $\mathrm{O}$ fato é que havia, nesse contexto, uma profunda divisão entre o ensino propedêutico e o ensino profissional - a ponto de não ser permitido nenhum tipo de aproveitamento de estudos entre ambos. Tal fato se deve à estrutura elitista do sistema educacional no país e da própria sociedade brasileira (MACHADO, 1989). Por um lado, o ensino propedêutico destinado às classes economicamente mais favorecidas para as quais se reservava também o ensino superior. E, por outro lado, o ensino industrial, meramente técnico, destinado à classe trabalhadora. Ou seja, a lógica do sistema educacional brasileiro, também se transpunha para o âmbito das indústrias.

O SENAI nessa dinâmica, divulgava constantemente as iniciativas do empresariado industrial destinadas ao processo formativo dos trabalhadores: seu objetivo era, em suas próprias palavras, "adestrar jovens empregados", adequando-os para o ritmo da produção industrial durante o processo de trabalho (treinamento na indústria):

Essa preparação escolar não poderia deixar de ser complementada com um estágio no próprio emprego, onde o aprendiz adquirirá então o adestramento necessário para o ritmo da produção industrial. Assim, o SENAI, para outorgar a Carta de Ofício de indica ter o menor completado a sua formação profissional, exige uma permanência do aprendiz na indústria, pelo menos durante 1 ano após sua formação escolar. A capacidade destas escolas, apesar de tão vasta rede de estabelecimentos de ensino profissional que o SENAI difundiu em todo o Brasil, nos seus 20 anos de existência, não podendo atingir, como é óbvio, a imensa plêiade de jovens trabalhadores das oficinas industriais as quais também precisam de ajuda na sua formação, levou o SENAI a pensar em outro tipo de atendimento à indústria, já agora através de uma ajuda aos empregadores na formação profissional dos menores, no próprio emprego. (REVISTA VIDA INDUSTRIAL, setembro-outubro, 1964, p. 20).

Nesse sentido, o ensino industrial para os trabalhadores da indústria era sinônimo de adestramento, para que os mesmos assimilassem o ritmo da produção. Tanto que no caso acima, até mesmo os estagiários e/ou aprendizes, eram desde o início, direcionados para aprenderem dentro da própria indústria. Foi assim que, visando atender cada vez melhor as demandas da indústria, o SENAI ampliava o seu programa de treinamento na indústria, enquanto forma de atendimento, para que os menores fossem "formados"/adestrados dentro do seu próprio emprego.

Foi então criado o Serviço de Treinamento na Indústria para o cumprimento de mais este objetivo. Esta ajuda se concretiza através de organizações de programas, com vistas à metodização da aprendizagem das técnicas de trabalho e da ordenação de um currículo para o ensino dos conhecimentos teóricos relacionados às práticas profissionais, sem 
olvidar da formação integral da personalidade do aprendiz no que diz respeito, principalmente, ao seu comportamento no trabalho, na sociedade e no lar. Aos mestres da indústria, os principais responsáveis pela formação dos aprendizes, o SENAI ministra os cursos básicos de T.W.I. isto é, ensino correto de trabalho, relações humanas e métodos de trabalho. Hoje em dia, grandes empresas já mantêm um sistema próprio de formação de mão de obra de que necessita, por meio de convênios com o SENAI. Por eles ficam as empresas com a possibilidade de reterem parte de sua contribuição e destiná-la a um fundo, criando centros de treinamentos que funcionam à base de intercâmbio SENAI-EMPRESA, sistema esse que ampliou consideravelmente a área de influência do SENAI. (REVISTA VIDA INDUSTRIAL, setembro-outubro, 1964, p. 21)

É factível nessa perspectiva que, a cisão no ensino brasileiro impactou fortemente na forma como se organizava o treinamento na indústria: ao operariado do chão de fábrica um reservava-se o adestramento e os mestres destinava-se uma formação para que eles aprendessem a ser formadores. O programa "Treinamento na Indústria" constituiu-se dessa forma, em um dos principais fundamentos da Pedagogia Industrial haja vista que se destinava a consolidar um processo educativo a partir do qual se ensinava o trabalhador no e para o trabalho: 1) a aprendizagem de técnicas específicas de trabalho; 2) a elaboração de um currículo que agregasse conhecimentos teóricos associados às práticas profissionais; 3 ) a adaptação da maneira de viver e de comportar no e para o trabalho.

Os mestres e instrutores que executavam a Pedagogia Industrial, enquanto responsáveis pela formação humana no âmbito da indústria, eram destinados, conforme expressa a fonte anterior, cursos básicos que ensinavam como trabalhar corretamente, além de apresentar as ações e estratégias utilizadas no trabalho a favor das relações humanas.

Mais que uma máquina, o homem tem falhas. E muito mais diversas. $\mathrm{E}$ de muito maior número. Surpreendentes. A introdução da Assistência Social da área da produção tem operado resultados tranquilizadores. A divulgação dos conhecimentos das Relações Humanas no trabalho, sua assimilação e aplicação por parte de chefes de setor, gerentes, capatazes ou homens mais diretamente responsáveis pelas equipes, também necessita entrar mais fundo naquelas áreas. A máquina deve ser lubrificada e funcionar à base de combustível ou de energia elétrica, para sermos simplistas. É fácil manejá-las. Suas deficiências, suas panes, seus enguiços são facilmente localizados e sanados. O mesmo não se dá com o homem, cujas reações variam de uns para outros. Que também sofrem desgaste, que falham e que, psicologicamente, não diagnosticam suas próprias deficiências, tarefa que deverá ser atribuída a outrem. Eis quando deve ser pronto, racional e humano o contato com esse trabalhador, no sentido de dirigi-lo, orientá-lo, removendo o motivo de um estado de espírito lesivo a si mesmo e aos interesses patronais. (REVISTA VIDA INDUSTRIAL, janeiro-fevereiro, 1964, p. 35)

Aos mestres e instrutores eram destinados, assim, os estudos acerca das relações humanas no trabalho, para que dessa forma, dificuldades nessa esfera fossem por eles solucionadas e até mesmo evitadas.

Em suma, essas ações, que compreendem o "Treinamento da Indústria" como a principal diretriz da Pedagogia Industrial, porém para a formação do operariado a ênfase era no adestramento do fazer e para a formação da gerência e técnicos especializados a 
ênfase era no gerenciamento do saber em favorecimento ao constante aumento da produtividade do trabalho.

Foi assim que, a escola da indústria, ou seja, o SENAI-MG teve como marco significativo o que já tivera destaque desde a década anteior, o programa de treinamento na indústria. Mas além disso, o SENAI-MG utilizava recorrentemente os espaços da RevistaVida Industrial para mostrar seu crescimento a partir de números. O fato que, para além do discurso de preparar mão de obra qualificada para o trabalhao na industria, o que se observa é que não era esta a prioridade, principalmente para a grande massa que constituía o operariado, que mais do que formação para executar seu trabalho, demandava, pelo viés do empresariado industrial mineiro, era de comportamentos padrões, alinhados aos imperativos das relações sociais de produção. "Em 1963, o SENAI mineiro entregou 177 cartas de ofício e 562 certificados de aprendizagem industrial. Convênio com M E C possibilitará ao SENAI atender 30 cidades firmando 5.200 jovens aprendizes." (REVISTA VIDA INDUSTRIAL, janeiro-fevereiro, 1964, p. 38).

Em grande parte dos espaços nos quais divulgava sua expansão em Minas Gerais, mecionava-se a parceria que o SENAI-MG estabelecia com o MEC, em prol da aprendizagem industrial e das previsões de crescimento.

\begin{abstract}
SENAI MINEIRO ESPECIALIZA 600 OPERÁRIOS
Para cumprir sua alta finalidade, ou seja, o preparo de mão de obra qualificada para a indústria, o Departamento Regional do SENAI, em Minas Gerais, mantêm escolas de aprendizagem localizadas em pontos de maior concentração industriária. São locais em que se ensina uma profissão, mas em que todos os aspectos da educação fazem se sentir através de uma orientação segura dentro das mais modernas técnicas pedagógicas. Este trabalho é feito em perfeita colaboração com as indústrias. Buscando cuidar também dos adultos, já empregados nas firmas do parque manufatureiro montanhês, o SENAI está atendendo a 600 deles dentro de um convênio firmado entre o Ministério de Educação e Cultura. Com a duração de cinco meses, sendo as aulas realizadas três vezes por semana, o objetivo de mais esta promoção do Senai é dar uma profissão definida àqueles operários que ainda não a possuem. (REVISTA VIDA INDUSTRIAL, janeiro-fevereiro, 1964, 51)
\end{abstract}

Um dos destaques do ano de 1964, foi o número de trabalhadores formados pela escola da indústria, ainda que insuficiente em contraposição às necessidades reais de mão de obra. E o que se destaca é o fato de que o SENAI-MG mantinha, estrategicamente, suas escolas de aprendizagem, onde era notável a concentração industrial, para que assim, se efetivasse a Pedagogia Industrial enquanto sinônima, neste caso, da aprendizagem de uma profissão a partir do que se referia enquanto as "mais modernas técnicas pedagógicas".

O ano de 1964 constitui um grande marco para a história política do país e seus respectivos desdobramentos abrangem uma série de fatores, tais quais se destaca a institucionalização do regime autoritário, essencial para a formulação e a execução da política econômica do governo, no sentido de dissolver quaisquer tentativas contrárias a esta estratégia.

Além disso, o planejamento e o controle eram palavras de ordem em todas as áreas governamentais, abrangendo até mesmo a tecnoburocracia, que respaldou as ações do Estado. Outro fator foi a criação de mecanismos formais e informais para garantir a estabilidade social necessária à acumulação do capital, dentre os quais, aqui se destaca o aprimoramento da Pedagogia Industrial, por parte do empresariado industrial mineiro; a 
contenção e o controle dos aparelhos sindicais, enfatizado apenas seu caráter assistencial e recreativo; etc.

\section{HOMENS DE EMPRESA CONVOCADOS PARA BATALHA DA PRODUTIVIDADE}

Homens de empresa foram concitados a empenhar-se na luta por melhores índices de produtividade através de ação planejada, emprego de equipamento e técnicas aperfeiçoadas e de racionalização do trabalho humano, numa conferência do Sr. Rafael Noschese, presidente da Federação das Indústrias de São Paulo, que foi lida pelo seu representante, Sr. Aristides Pilleggi, na abertura do "Mês da Produtividade" promovido pelo Centro de Produtividade Industrial da FIEMG. A reunião na Federação das Indústrias, que teve também o início de mesas redondas com o técnico norte-americano, Sr. James W. Quigg, sobre produtividade industrial, foi presidida pelo Sr. Fábio Araújo Motta, estando ainda presentes numerosos diretores e associados da entidade de classe. O Sr. César Rodrigues, diretor do Departamento de Produtividade da FIEMG, fez uma saudação ao representante do Sr. Rafael Noschese, que vinha de ser distinguido pelo Instituto Superior de Estudos de Liderança e Direção com o título de "Líder do Ano". O Sr. Aristides Pilleggi, que é diretor do Centro de Produtividade Industrial da FIESP, começou por destacar que as Classes Produtoras, por intermédio dos seus órgãos representativos, decidiram levar a efeito uma campanha intensiva que tomou o nome de "Mês da Produtividade". Esse movimento se estendeu a vários Estados, objetivando o esclarecimento, debate e orientação dos problemas de produtividade na indústria. [...]. Salientou que o mundo se industrializava rapidamente, enquanto milhões de indivíduos ingressam nas atividades industriais ou para elas se deslocam, vindos do meio rural. $\mathrm{O}$ processo de urbanização, quase sempre tumultuado, provoca os inevitáveis desequilíbrios e carências. Por isso mesmo, regiões cada vez mais extensas do globo se defrontam com problemas difíceis. Disse que estudos estatísticos permitem uma apreciação mais completa do fenômeno da industrialização e que a ampliação geográfica das áreas de expansão industrial passou a depender de condições as mais variadas. [...] Todavia, o confronto entre distribuição geográfica da população industrial e o volume de produção continua a revelar contrastes acentuados. (REVISTA VIDA INDUSTRIAL, novembro-dezembro, 1964, p. 56)

Como se observa na fonte, o capital estrangeiro se fazia fortemente presente, sobretudo os Estados Unidos, sempre ativo nos planejamos e ações educacionais da FIEMG. Tanto que a produtividade se tornou palavra de ordem e muito almejada nos interesses patronais da indústria mineira. $O$ objetivo era consolidar de vez a industrialização no estado.

\section{ENÉRGICO MANIFESTO - CLASSES PRODUTORAS CONDENAM SINDICALISMO SUBVERSO}

As classes produtoras de Minas Gerais, através de suas entidades de classe, endereçaram aos Poderes da República incisivo pronunciamento em que pedem tranquilidade para o trabalho, condenando a inflação desenfreada, a indisciplina, as espúrias organizações e o "sindicalismo revolucionário". O importante documento teve a maior repercussão no seio da opinião pública do País. Visando pleitear reformas que devem ser 
estudadas e feitas dentro da ordem e da legalidade, instalou-se na vida nacional uma estrutura maligna, que lhe corrói a resistência e certamente irá leva-la ao aniquilamento, se a sua extirpação não se fizer antes que a metástase torne inócua a mais enérgica das terapêuticas. (REVISTA VIDA INDUSTRIAL, novembro-dezembro, 1964, p. 62)

Quanto ao controle dos aparelhos sindicais, em consonância com o contexto político do regime militar à frente do governo nacional, o empresariado industrial nacional e demais frações que compunham as classes produtoras mineiras, foram chamados para se opor ao sindicalismo revolucionário por eles tachado de subversivo. $\mathrm{O}$ objetivo era que o empresariado, pregando a paz e a tranquilidade para o trabalho (ou para a produtividade?), exterminar o que atrapalhasse a ordem rumo ao desenvolvimento do país. Sustentado num discurso positivista de cunho organicista, o sindicalismo era sinônimo de doença.

É esse "sindicalismo revolucionário e contra a lei" que aspira, como já se notou, a ser um super-poder. Mas um super-poder que não seria moderador e sim a insubmissão; não impeliria à evolução, mas plantaria a revolução; não reformaria para melhor porque quer antes destruir do que construir. $\mathrm{O}$ aniquilamento da ordem jurídica é seu objetivo, porque ela é a disciplina que tolhe os excessos, é a norma de conduta, que impede o esmagamento da maioria pela minoria em que se constitui é, em fim, o obstáculo à submissão do País ao processo revolucionário. Essa condescendência avilta o poder político e traz o mais seguro caldo de cultura à desorganização econômico-financeira, pródromo da desordem social e das soluções revolucionárias. É preciso por um paradeiro à agitação organizada, impõe-se a restauração do princípio de autoridade para que novamente impere a ordem e se possibilite o progresso. (REVISTA VIDA INDUSTRIAL, novembro-dezembro, 1964, p. 55)

Sob a justificativa de resguardar a ordem e o progresso, o sindicalismo, sob a ótica do empresariado industrial, deveria ser curado, por apresentar a possibilidade de desestabilizar tanto a esfera econômica, quanto a esfera política.

Minas Gerais não pode ver o desenvolvimento da imensa crise em que se debate o País, sem essa advertência aos responsáveis pela condução da sua política para que não se deixem levar pelas inspirações das paixões e interesses momentâneos, mas antes se orientem pelos supremos objetivos da Nação, com os quais só se harmonizam as soluções ditadas pelo equilíbrio que impõe o mais grave senso da ordem. Por todas essas razões, associando as nossas vozes às das Classes Produtoras de São Paulo, fazemos nossa sua conclamação: “com a responsabilidade de manter centenas de milhares de empresas em produção; de assegurar milhões de empregos; de garantir receita pública, é nosso dever, nesta hora grave da nacionalidade, conclamar os Poderes da República - o Congresso, o Executivo e o Judiciário, a que não se omitam e nem se demitam de suas prerrogativas constitucionais e não permitam o vilipêndio dos nobres propósitos que a Nação, pela lei lhes confiou". (REVISTA VIDA INDUSTRIAL, novembro-dezembro, 1964, p. 56) 
Apelando que o sindicalismo dito subversivo poderia colocar em xeque todo o desenvolvimento econômico obtido até então, o empresariado industrial solicitando apoio até mesmo à classes produtoras de outros estados, utilizou-se do nacionalismo para combater a organização dos trabalhadores em sindicatos, para que eles não acordassem da sua condição alienante, imposta pelo trabalho precarizado e pela Pedagogia Industrial que adentrava no processo produtivo e nas relações sociais de produção.

"Colegas, iniciamos 1964 com um déficit de 130 milhões, pois o nosso compromisso com as máquinas importadas é de nada menos que 110 milhões ao dólar de mil cruzeiros. Sabemos ter mais um ano difícil a enfrentar, razão por que consentimos em continuar na Presidência do Conselho Regional". -afirmou o Presidente do SENAI. (REVISTA VIDA INDUSTRIAL, janeiro-fevereiro, 1964, p. 34)

Todos estavam convocados para a recuperação da crise econômica, principalmente o empresariado industrial, investindo massivamente na produtividade e direcionando todos os seus esforços para o que logo em seguida se caracterizou de milagre econômico. Porém o milagre seria temporário, pois era nítido o alto preço do crescimento econômico com os números dos investimentos que posteriormente se configuraria na dependência e no endividamento externo.

Dois anos de crise: a indústria sente-se insegura: "Precisamos de reformas de caráter e de paz alicerçada na decência". Finalmente: "que o Brasil precisa de paz para o trabalho, paz que não é conquistada a qualquer preço, mas de paz alicerçada na decência com normas de administrador com rigor, na defesa do interesse democrático e isso é que a Federação das Indústrias do meu Estado tem feito através de dois Fóruns". (REVISTA VIDA INDUSTRIAL, abril-julho, 1963, p. 02)

Neste contexto de crise, o empresariado industrial expôs a insegurança da indústria mediante tamanha instabilidade, solicitando de que a paz se faz necessária para o trabalho e para a indústria enquanto "criadora de riquezas".

Acrescentou o presidente da FIEMG "que os patrões brasileiros são cognominados, numa gíria, tecnicamente dirigida de gorilas de reacionários, de homens que não entendem o fenômeno social, de hoje agarrados por egoísmo àquela situação de não acreditar em evolução, na análise de que hoje é a antecipação daquilo que vai acontecer amanhã. Todos nós sabemos que isto não é verdade - frisou - pois, os homens de empresa, principalmente da indústria, que é uma atividade criadora de riquezas, já somos por convicção e não por virtude, e por dever, socializados neste País, e, haja vista que as conquistas da legislação social, criadas por um líder trabalhista, os ônus e os Institutos, o salário família, o $13^{\circ}$ salário, a indenização, a estabilidade, enfim, todo o arcabouço jurídico constitucional do direito do empregado, representa, sem sombra de dúvida, uma conquista que não há empregador que se oponha a ela". (REVISTA VIDA INDUSTRIAL, abril-julho, 1963, p. 05)

Com o desenvolvimento econômico estancado e com uma série de condições propícias para avançar e crescer, o empresariado industrial mineiro manifestou sua preocupação, para o presidente da república João Goulart, quanto à instabilidade e 
estagnação, solictando reformas, que viriam acontecer em 1966, rumo ao milagre econômico. Havia também uma recorrente preocupação com as manifestaçõess comunistas, ao mesmo tempo que também se fizera questão de destacar os avanços ocorridos nos direitos trabalhistas, o que revelava a estratégia de cooptação da classe trabalhadora, para que a mesma não se manifestasse contrariamente a este movimento.

$\mathrm{O}$ fato era que o governo pregava o distanciamento do socialismo soviético. Tanto que, no ano de 1963 não havia no Brasil a convicção que instaurava-se uma ditadura militar. Mesmo com o golpe, a ditadura somente fora percebida com o endurecimento do regime na segunda metade da década de 1960.

Os indícios do posterior auge de desenvolvimento que seria atingido após a crise de 1964, já se destacavam nos anúncios do empresariado industrial mineiro, no âmbito da educação. Nos moldes da Teoria do Capital Humano, tinha-se como meta multiplicar os números da qualificação profissional de trabalhadores para a indústria em parceria com o MEC.

\section{POSIÇÃO DO BRASIL}

Excluída a Rússia, sobre a qual faltam dados preciosos - continuou o Sr. Aristides Pilleggi - setenta e cinco por cento da produção industrial do mundo estão concentrados, praticamente, em seis países: Estados Unidos, Inglaterra, Japão, Alemanha, França e Itália. Abrigando apenas 17 por cento da população do globo, esses países ocupam, entretanto, sessenta por cento de toda população industrial - cerca de cinquenta milhões de empregados. Os demais estão disseminados em oitenta e um países. Pertencemos, no Brasil, a uma região do mundo que apenas desperta para a industrialização, com exceção de poucas áreas que se aproximam das mais evoluídas. Abrem-se, entretanto, neste Continente as mais amplas perspectivas para a aplicação das técnicas nacionais de organização e de produtividade.

\section{INTEGRAÇÃO}

O diretor do Departamento de Produtividade Industrial da FIESP afirmou que uma grande tarefa está à nossa frente - a integração socioeconômica de vastas regiões do território nacional, pela supressão ou redução dos contrastes e diferenças ainda existentes. Não é demais atentarmos - frisou - para as discrepâncias entres os valores regionais da renda interna. Assinalou que é inadiável fortalecer e expandir os atuais Departamentos de Produtividade da Indústria e criar um organismo superior, de âmbito nacional, com participação dos setores governamentais, da economia privada e da classe trabalhadora. A esse organismo, cujas funções seriam normativas, consultivas e de coordenação, caberia promover pesquisas de caráter nacional e estabelecer as diretrizes gerais da política de produtividade no País. (REVISTA VIDA INDUSTRIAL, janeirofevereiro, 1964, p. 58)

Tanto que nesse momento, a Revista Vida Industrial veiculou explicitamente o "passe livre" para o capital estrangeiro tanto em Minas Gerais quanto no Brasil, enfatizando-se também, a abertura da FIEMG e das indústrias mineiras para a aplicação de técnicas focadas no aumento da produtividade. E o carro chefe deste objetivo era o Departamento de Produtividade das federações representativas do empresariado industrial visando a implementação, em âmbito nacional, de uma política de produtividade.

Essa abertura para o capital estrangeiro provocou também a expansão e a consolidação das empresas multinacionais no país, período no qual acentuou-se o processo 
de concentração de capital em detrimento da formação de conglomerados financeiroindustriais e também as transformações na estrutura do sistema empresarial brasileiro. $\mathrm{O}$ que contribuiu para este marco foram dois fatores: 1) a política anti-inflacionária, eu penalizou a pequena, a média e parte da grande burguesia; 2) as iniciativas que garantiram a instalação e a ampliação das empresas estrangeiras no Brasil (SINGER, 1976). O capital nacional privado tinha então que se movimentar entre a busca pelos seus interesses, buscando parcerias com o capital internacional privado, mas ao mesmo tempo opondo-se a ele, em detrimento da prioridade no seu crescimento.

Num momento onde se censurava os meios de comunicação, aqueles que representavam os interesses econômicos capitalistas, tinham passo livre: é o caso da Revista Vida Industrial, que difundia, a favor do processo de acumulação do capital, os interesses da indústria mineira representada pela FIEMG.

Mas além de dedicar-se ao processo formativo dos trabalhadores, a FIEMG em parceria com o SESI-MG, organizou também uma série de planos e ações que abrangiam não só o trabalho, mas a vida como um todo dos trabalhadores da indústria, porém com a mesma finalidade do SENAI-MG: realçando o processo educativo de valorização do trabalhador utilizando-se de meios diferentes da aprendizagem industrial.

\section{SESI: ESFORÇOS CONJUGADOS PARA PROMOVER BEM ESTAR SOCIAL \\ Para dinamizar a assistência prestada à família industriária, o Serviço Social da Indústria, em Minas Gerais, vem procurando descentralizar cada vez mais os seus serviços, tanto assistenciais como educacionais. A assinatura de convênios com várias instituições públicas e particulares é uma das medidas adotadas nesse sentido. Permite alcançar um número considerável de beneficiários, em locais mais próximos de suas residências e mesmo das firmas em que trabalham. Dessa maneira, o SESI vai ao encontro dos operários, levando-lhes seus serviços, com despesas menores e consequentemente maiores possibilidades de expansão. O trabalho em convênio data de 1960. As constantes solicitações feitas à Entidade, por parte de empresas, obras sociais, associações de classe e similares, atestam as vantagens da providência tomada. (REVISTA VIDA INDUSTRIAL, setembro-outubro, 1964, p. 52)}

Em termos pormenores, o SESI-MG conjugava seus esforços e ações na tentativa de promover o bem estar social do trabalhador por meio de um processo educativo, que também se integrava aos propósitos da Pedagogia Industrial. Para isso, uma de suas estratégias foi a busca pelo firmamento de convênio com várias instituições educacionais e assistências, visando dessa forma, oferecer para os trabalhadores da indústria dispersos pelo estado de Minas Gerais, o atendimento próximo de suas casas ou então do seu local de trabalho. Essa ação foi fomentada desde o início da década de 1960, porém foi em 1964, que iniciaram os seus efeitos. Foi uma decisão que surtiu efeitos positivos para o SESI-MG e para a FIEMG.

MAIOR ASSISTÊNCIA MÉDICA AOS OPERÁRIOS DA INDÚSTRIA De início, a entidade preocupou-se com seu programa atual: Saúde Educação - Recreação (SER). As condições de vida do industriário e ainda a falta de recursos assistenciais levaram o SESI a dar ênfase ao plano assistencial médico, dentário e social. Com a promulgação da Nova Lei Orgânica da Previdência Social, a responsabilidade curativa ficou os 
IAPs, cabendo ao SESI e entidades correlatas o desenvolvimento de atividades educacionais. Enquanto que os órgãos da Previdência Social entravam em campo de necessitando de material e instalações, o SESI dispunha de modernos ambulatórios espalhados por todo o Estado. Sobretudo o Conjunto Assistencial "Esther de Araújo Motta" é tido como um dos mais completos das América do Sul. Equipados os núcleos assistenciais da obra contavam ainda com pessoal técnico altamente especializado. (REVISTA VIDA INDUSTRIAL, setembro-outubro, 1964, p. 60)

O SESI-MG, em parceria com o IAPI (Instituto de Aposentadorias e Pensões dos Industriários), firmou um acordo intermediado pela FIEMG, que ofertava atendimento médico para o operariado industrial mineiro. Ora, era vantajoso utilizar da estrutura do SESI-MG juntamente com os subsídios infra estruturais do IAPI para evitar que o trabalhador adoecesse e assim deixasse de trabalhar. O interessante é que essa ação pertence ao programa SER (Saúde - Educação - Recreação) fomentado, elaborado e consolidado pelo SESI-MG promovendo atendimento médico, dentário e social. Ou seja, o programa SER constituiu, neste contexto, em outra diretriz da Pedagogia Industrial do empresariado mineiro, em defesa da educação do corpo e da vida do trabalhador.

\section{EDUCAÇÃO}

Em qualquer atividade o SESI dá realce ao processo educativo como meio de valorização do trabalhador. A obra educativa do SESI se orienta no sentido de que a vida em sociedade se realize e de forma comunitária. META PRIMODIAL DO SESI

O Serviço Social da Indústria SESI tem uma finalidade precípua que é a promoção da pessoa que trabalha nas fábricas e similares. A própria Portaria do Ministério do Trabalho, de 30 de julho de 1962, regulamenta os seus principais objetivos: alfabetização do trabalhador e de seus dependentes; educação de base; educação para a saúde física, mental, e emocional; educação para a economia; educação familiar; educação moral e cívica e educação comunitária e o Departamento Regional de Minas Gerais vem procurando atendê-los de maneira objetiva e imediata. Para isto, aumenta o número de seus Centros Sociais, oferece melhores acomodações e maiores possibilidades para a dinamização dos cursos e atividades educacionais promovidas por eles.

\section{CURSOS E MATRÍCULAS}

O pensamento inicial foi não divorciar o industriário de sua família e ainda mais, procurar fortalecer os seus laços e oferecer-lhe oportunidades para melhoria das condições de vida. Esposas, filhas, irmãs, mães de industriários ao lado dos operários encontraram nos cursos do SESI uma oportunidade de promoção e mostraram-se capazes de trazer os outros membros da família para um local sadio, dotado de várias atividades capazes de preencher satisfatoriamente as horas de lazer de cada um. Outros cursos foram surgindo dentro das solicitações e interesses locais, dando aos Centros Sociais atividades próprias e variadas. No que concerne a cursos permanentes, o SESI, no momento, possui 49 de formação doméstica, em Minas Gerais tendo 3.388 alunas matriculadas em 1963. Em apenas dez anos de atividades ultrapassou a casa de um milhão de diplomadas nos cursos de bordados, decoração do lar e corte e costura. (REVISTA VIDA INDUSTRIAL, janeiro-fevereiro, 1964, p. 61) 
Assim, o que se destaca em relação ao SESI-MG, é sua ênfase enquanto obra educativa voltada para a valorização do trabalhador, a partir do processo educativo propriamente dito, gerido pela FIEMG. Por mais variada que fosse a assistência que o SESI-MG disponibilizava ao trabalhador da indústria mineira, sua essência era, portanto, educativa. Nesse sentido, a Pedagogia Industrial do SESI-MG, consistia especificamente em: alfabetizar os trabalhadores e seus dependentes; promover a educação de base; atendimento em educação para a saúde (mental, física e social); educação para a economia; educação familiar; educação moral e cívica; educação comunitária - o que em síntese disciplinava o trabalhador, sua vida e sua família para o exercício do seu trabalho.

Outro órgão do SESI-MG de cunho essencialmente educativo, era o SEOS (Serviço de Educação e Orientação Social), pertencente à DSS (Divisão de Serviço Social) e que tinha como meta concretizar os objetivos do SESI, que se resumem na busca pela paz social.

\section{O QUE É SEOS}

O Serviço de Educação e Orientação Social - SEOS - tem como finalidade colaborar para o desenvolvimento da pessoa humana em várias dimensões, procurando conhecer suas necessidade, despertando e preparando o homem para as suas responsabilidades sociais, levando-o a participar mais eficazmente do progresso econômico e social da comunidade da qual faz parte, usando como instrumentos de trabalho: 1) organização e desenvolvimento de comunidade de base; 2) orientação de grupos no sentido de levar seus participantes de uma atitude passiva para um atitude consciente, que por sua vez, deve conduzir à ação; 3) ensino de várias técnicas manuais e conceitos de formação social, doméstica, moral e cívica para o enriquecimento das pessoas e fortalecimento da família. (REVISTA VIDA INDUSTRIAL, janeiro-fevereiro, 1964, p. 65)

O SEOS consistia em mais uma diretriz da Pedagogia Industrial do empresariado mineiro voltada ao "desenvolvimento humano" em suas múltiplas dimensões, sob a justificativa de que o trabalhador da indústria contribuísse efetivamente para o progresso econômico e social do Brasil pela elevação da produtividade. Para isso, o SEOS tinha como objetivos: elaborar e desenvolver uma comunidade de base; orientar grupos de trabalhadores quanto à passividade em suas ações; ensinar saberes voltados para o disciplinamento do trabalhador. Tais desígnios eram convergentes com os objetivos do SESI-MG. E as atividades previstas nestes objetivos eram concretizadas nos Centros Sociais, Centros de Atividades e Cursos Isolados pertencentes ao SESI-MG, que de tempos em tempos, eram expostos para a apreciação do empresariado industrial mineiro e demais interessados (REVISTA VIDA INDUSTRIAL, janeiro-fevereiro, 1964).

Os Centros Sociais, nessa lógica atuavam fortemente e prol das ações educacionais circunscritas ao SESI-MG. Eram neles que se desenvolviam grande parte dos planejamentos e atividades propostas. Ou seja, o aprendizado oferecido pelo SESI-MG ocorria nos Centros Sociais. E os produtos dessa aprendizagem, eram organizados em exposições, para divulgar o trabalho do SESI-MG no âmbito do empresariado industrial mineiro, que inclusive aconteceram no próprio espaço da FIEMG.

Os Centros Sociais desempenham um papel preponderante no desenvolvimento das atividades educacionais de responsabilidade do SESI, pois é por intermédio deles que se realiza toda uma técnica a serviço do bem estar coletivo, objetivando a elevação do padrão de vida 
do industriário e de seus dependentes. (REVISTA VIDA INDUSTRIAL, maio-junho, 1964, p. 67)

O SESI-MG também atuou fortemente no aprimoramento físico do corpo dos trabalhadores, o que também era extremamente importante e favorável para o desempenho do trabalho na indústria, sobretudo as atividades que demandavam esforço físico. Eis então a importância da referência ao esporte, que também se associava ao lazer.

E por quê não canalizar esta tendência, este gosto pelo esporte em favor da educação, do desenvolvimento de outras potencialidades humanas? Simplesmente, preenchendo horas de lazer o esporte pode e deve constituir um meio para preparar e capacitar os homens levando-os a oferecer uma resposta decisiva às exigências da vida prática. Ainda permite a procura de uma fórmula democrática de convivência para a realização de fins comuns, dentro da natural sociabilidade humana. Ritmo, graça, harmonia, cores e beleza no preenchimento sadio de horas de lazer. (REVISTA VIDA INDUSTRIAL, janeiro-fevereiro, 1964, p. 67)

A própria fonte acima revela, na ótica empresarial, a importância do incentivo ao esporte, ressaltando que tratava-se de um meio de preparar e de capacitar os homens para o processo de trabalho, ainda sob o discurso de caminhar rumo à democracia - desde que não afestasse os interesses particulares e utilitários do empresariado industrial mineiro, dos propósitos de acumulação do capital e do Estado.

A ênfase no esporte enquanto um dos objetivos do SESI-MG, visava a educação para a saúde física, mental e emocional do trabalhador, oferecendo atividades para crianças, adolescentes e adultos. Neste caso, também estava ligada ao SEOS, e especificamente ao SRF (Setor de Recreação Física).

\section{TEATRO COM OPERÁRIO E PARA OPERÁRIO}

Já em civilizações antigas o teatro era considerado como um excelente veículo para a educação, uma verdadeira arte em que a imaginação funciona tanto na vivência de um personagem como na análise de uma peça. Verdadeiras lições são encontradas nos diálogos gregos e nas peças da idade média. Na idade moderna diversos escritores e filósofos dos mais conceituados apresentam suas ideias, esclarecem o povo, interpretam fatos e personagens, analisam e tiram conclusões. O teatro é uma maneira de disseminar cultura e defender atitudes necessárias. Bem orientado, diverte instruindo e instruí divertindo. Além do intercâmbio entre centros sociais do próprio SESI e de outras Entidades similares, o teatro vem sendo assim um veículo para desenvolvimento da capacidade criadora, treinamento para uma vida democrática, cultivo do gosto artístico, aprendizagem através dos espetáculos, sociabilização aquisição de novas habilidades e ainda confraternização. (REVISTA VIDA INDUSTRIAL, janeiro-fevereiro, 1964, p. 68)

Outro elemento circunscrito ao processo educativo instaurado pelo SESI era a cultura, também associada ao lazer. Nesse caso, o que se destacou em 1964 foi o trabalho com teatros, voltados para a classe trabalhadora e também desenvolvidos por esta mesma classe. O importante era que com isso, os trabalhadores apreendessem os princípois de 
disciplinamento para o trabalho e também de convívio social. O que chegava a ser contraditório e incoerente era a Revista Industrial divulgar em pleno período de censura e de conteção social (1964) que tinha à sua frente o governo militar, a questão da vida democrática, ainda que sob uma lógica utópica ou meramente discursiva.

As atividades, em 1964, prometem ainda mais do que nos anos anteriores. Uma coisa é certa: tudo isto é apenas um pouco do muito que o Serviço Social da Indústria - SESI- vem estudando, planejando e executando, contribuindo para o bem-estar dos trabalhadores na indústria, concorrendo para a melhoria do padrão de vida no país e para o aperfeiçoamento moral e físico da família operária ao lado do desenvolvimento do espírito de solidariedade entre as classes. (REVISTA VIDA INDUSTRIAL, janeiro-fevereiro, 1964, p. 70)

A previsão para o ano de 1964 era a ampliação de uma série de atividades voltadas para o esporte. Todas essas ações, que fazem parte da Pedagogia Industrial, visavam, tal como expressa a fonte acima, o aperfeiçoamento moral e físico do trabalhador da indústria e de sua família.

Assim é que, depois do "Curso de Gerência", a cargo de "Manegement Center do Brasil": do "Seminário de Psicologia da Direção", para dirigentes e chefes; "Técnicas Básicas de Administração de Pessoal", todos nos últimos meses, foi realizado o curso de "Almoxarifes Industriais". Uma promoção do Centro de Produtividade da FIEMG, com a colaboração do Centro Nacional de Produtividade na Indústria e do Instituto de Racionalização do Trabalho. (REVISTA VIDA INDUSTRIAL, janeiro-fevereiro, 1964, p. 68)

Em suma, os projetos e ações educacionais do empresariado mineiro representado pela FIEMG e que compuseram a Pedagogia Industrial entre 1963 e 1964, correspondiam ao lançamento de cursos, seminários e palestras voltados para a produtividade da indústria e consequentemente para o desenvolvimento econômico mineiro e brasileiro.

Essas foram, as principais atividades que o SESI-MG desenvolveu no ano de 1964, destacando que era emergente a necessidade de ir além, em prol do bem-estar do trabalhador da indústria mineira que consequenetemente, acarretaria também, uma série de benefícios para a indústria propriamente dita e para o denvolvimento econômico do estado e do país, em alinhamento ao regime de acumulação de capital - o que contribuiu também para a efetivação no Brasil do capitalismo dependente, desigual e combinado.

$\mathrm{O}$ fato é que o eixo condutor de tantas mudanças consiste nas próprias necessidades do desenvolvimento econômico, uma vez que o sistema produtivo demandava que as escolas fossem a ele adaptadas e adaptáveis sempre que preciso. Eis portanto a necessidade da participação e/ou envolvimento direto dos empresários com a direção das escolas.

Apesar de todas as suas limitações, a escola é vital para o trabalhador e para seus filhos, na medida em que ela se apresenta como uma alternativa concreta e possível de acesso ao saber. E é só a partir das pressões que estabelecerá no seu interior, aliada aos esforços dos intelectuais progressistas e orgânicos, que a classe trabalhadora poderá força-la à democratização. (KUENZER, 1989, p. 190) 
Tanto que nesse sentido, era explícito o empenho do SENAI-MG em articular/alinhar a indústria e as escolas, para que aos futuros trabalhadores fosse viabilizada a experiência de contato com o ambiente de trabalho em consonância pela ávida busca pela produtividade.

\begin{abstract}
Mas, não ficou aí a remodelação da aprendizagem. Outros alunos, aqueles que recebem ensinamentos na escola, necessitavam também conhecer o ambiente da indústria, visando uma maior integração quando do trabalho efetivo. E assim é que, recentemente, a Escola do SENAI, na Cidade Industrial firmou convênio com a Cia. Siderúrgica Belgo-Mineira. Este convênio implica na execução de trabalhos industriais em ritmo acelerado, mediante encomendas industriais, com maior aproveitamento da moderna maquinaria. Através disto, oferece-se, aos alunos, campo para manuseio idêntico ao da fábrica e ainda ajuda às indústrias no atendimento das exigências imediatas da produção. (REVISTA VIDA INDUSTRIAL, janeiro-fevereiro, 1964, p. 71)
\end{abstract}

Entremeio a tais ações, com o expurgo à democracia e ao populismo, fazia-se necessária, uma nova sustentação do regime militar.

O grupo militar que tomou o poder em 1964 vinha de uma tradição militar mais antiga, que remonta à participação do Brasil na II Guerra. A participação do Brasil ao lado dos países aliados, acabou sedimentando uma estreita vinculação dos oficiais norte-americanos e militares brasileiros, como os generais Humberto de Castelo Branco e Golbery Couto e Silva. Terminada a guerra, toda uma geração de militares brasileiros passaram a freqüentar cursos militares norte-americanos. Quando esses oficiais retornavam dos EUA, já estavam profundamente influenciados por uma concepção de "defesa nacional". (PRIORI, 2004, p. 15)

Espelhada na estrutura norte-americana, foi fundada, neste contexto, a ESG (Escola Superior de Guerra), vinculada ao Estado Maior das Forças Armadas. Foi dentro dessa escola que foram formulados os princípios da Doutrina de Segurança Nacional, dentro da qual se destacou o SNI (Serviço Nacional de Informações). Em 1968, essa doutrina tornouse lei, objetivando identificar e eliminar todos que eram contra o regime militar, ou seja, os "inimigos internos" ou comunistas. Todos estes aspectos estruturaram uma nova ordem de poder e de controle social, que em suma se consolidou com o Ato Constitucional $\mathrm{n}^{\mathbf{o}} 1$ (PRIORI, 2004).

Durante a ditadura militar foram editados 17 atos institucionais. Mas entre eles, o mais polêmico e violento foi o de Número 5. O AI-5, editado em 13 de dezembro de 1968, reedita os princípios do AI-1, suspende o princípio do habeas corpus e institui de forma clara e objetiva a tortura e a violência física contra os opositores do regime. Na verdade o AI-5 simbolizou um forte ciclo de repressão com amplos expurgos em órgãos políticos representativos, universidades, redes de informação e no aparato burocrático do Estado, acompanhados de manobras militares em larga escala, com indiscriminado emprego da violência contra todas as classes. (PRIORI, 2004, p. 17, grifos do autor) 
Os atos institucionais, aliados ao autoritarismo severo dos militares respaldavam o trabalho das forças repressivas e seus respectivos órgãos de repressão contra todos aqueles que se opusessem ao regime militar.

Uma das reflexões possíveis que tange a especificidade do governo militar brasileiro, refere-se a forma como o regime autoritário foi arquitetado no país. O regime foi articulado por uma notável ambiguidade, pois mesmo no exercício de um regime de exceção e essencialmente enfatizado por uma indelével "lógica da suspeição", os dirigentes procuravam legitimá-lo e caracterizá-lo como sendo um sistema de governo democrático. Do primeiro general-presidente (Humberto de Alencar Castello Branco) até o último (João Baptista de Oliveira Figueiredo) foi salientado, principalmente, nos discursos de posse dirigidos ao povo brasileiro, a adoção de ações e comportamentos em nome da defesa da democracia no país. Por outro lado, constatou-se, ao longo de vinte e um anos de permanência dos militares no poder, que a existência de uma administração democrática foi apenas fictícia, haja vista o contundente papel repressor desempenhado pelos órgãos policiais e jurídicos a fim de suplantar possíveis distúrbios sociais que afetassem o andamento das atividades do Poder Executivo. (PRIORI, 2004, p. 22)

Em outras palavras, a Doutrina de Segurança Nacional e Desenvolvimento (DSNeD), constituiu a fundamentação ideológica do Estado Autoritário próprio do regime militar. A DSNeD estruturou as atividades de informações/contra-informações e a repressão do regime militar, sempre em contraposição ao "inimigo interno" que pudesse colocar em risco a segurança nacional. Foi a partir disso que constituiu-se também, em articulação à DSNeD, a Comunidade de Informações, voltada para a Espionagem política.

\section{AINDA EXISTIRÁ CAPITALISMO?}

Em um se seus livros mais expressivos, (Prefácio da Crítica da Economia Política), Marx professa certas ideias no mesmo estilo autoritário de todos os outros escritos. O filósofo não possui a flexibilidade de Engels e nem conduz com forma de pensar assumida por Lenine, cuja mentalidade é dialética, no sentido da filosofia política que adotaram. (REVISTA VIDA INDUSTRIAL, abril-julho, 1963, p. 33)

Um exemplo da implementação da $\mathrm{DSNeD}$, foi o expurgo, na Revista às manifestações marxistas, tal como se apresenta acima onde curiosamente se critica Marx, porém destacando a "flexibilidade" de Engels, certamente pela sua hereditariedade - filho de dono de indústria.

Foi construído, nessa dinâmica, um amplo discurso, dispensando a implementação do Código do Trabalho. Num contexto de ditadura, além de reprimir manifestações democráticas e populistas, se reprimia também, no âmbito da indústria, quaisquer ideias ou ideais favoráveis ao direito do trabalhador.

O governo de Médici (1969-1974) foi considerado o período de maior repressão do regime militar, porém também foi estimado como o período designado de "Milagre Econômico", em virtude do notável crescimento econômico, que por seu turno, reduziu o impacto das medidas de segurança adotadas pelo governo. Este período de ditadura militar até hoje ainda possui aspectos obscuros, marcado pela repressão, pelo autoritarismo e pelo nacionalismo exacerbado. 
O Brasil para Singer (1976), nesse contexto, foi mediador entre o centro e os países periféricos. E como consequência, acentuou-se ainda mais a condição de dependência do país, que a partir de então dependia também dos países importadores do centro, dos equipamentos e tecnologias e também das matérias primas, necessárias para este processo de acumulação de capital à brasileira. E além disso, controlou-se também os custos com mão de obra, visando favores a reprodução do capital, ampliando suas taxas de lucro.

O problemas da dependência, visto por este ângulo dos objetivos econômicos visados e que, em última análise, se constituem nos módulos principais da situação, pode ser classificado a partir de pelo menos três formas de ação. Estas correspondem, por sua vez, a duas etapas historicamente distintas. A primeira dessas formas de ação se expressa através da luta por territórios econômicos, visando a apropriação de matérias-primas e/ou de mercados locais para produtos manufaturados nos pólos de dominação; a segunda se caracteriza pela fase de exportação de capital (industrial ou financeiro) do centro para a periferia; a terceira, e mais recente, pelo investimento estrangeiro com apropriação de fatores de produção existentes nas áreas periféricas; e no controle, por dentro delas, dos mercados nacionais. (MARTINS, 1968, p. 41)

No que se refere ao desenvolvimento brasileiro, em suma, são três grandes fatores que configuraram a estratégia de ação direcionada para o Brasil: a concentração de capital a internacionalização da economia e a contenção salarial. E a ela se soma, no estado de Minas Gerais, a partir da FIEMG, a oferta das bases técnicas e ideológicas necessárias para a expansão do capitalismo dependente.

A partir de 1964 o ensino técnico e a educação brasileira em geral, como elementos componentes da superestrutura social, passam a se reorganizar no sentido de atender às novas necessidades criadas pela transformação na base econômica, qual seja, as transformações operadas para dinamizar a economia na direção do avanço da (re)produção da acumulação capitalista, agora ainda mais integrada ao capitalismo a nível mundial (MACHADO, 1989, p. 66).

E em relação ao processo de industrialização, estes três fatores consistem em diferentes ações e reações que geram a situação de dependência. O interessante é que em dois de tais fatores, é nítida a presença de capital privado estrangeiro: tanto na busca por mercados e/ou matéria prima, quanto no foco em investir capital estrangeiro na produção localizada em periferias (em busca de mão de obra barata). "Havia uma aspiração por indústrias típicas de economias maduras e que, ao mesmo tempo, não contrariassem os interesses do capital privado nacional, de maneira que o capital estrangeiro foi bem-vindo." (FILHO, 1994, p. 33)

Ou seja, a diretriz norteadora do ensino técnico e também da Pedagogia Industrial propriamente dita, eram, naquele momento, os imperativos econômicos capitalistas. Os rumos do empresariado industrial e dos seus projetos educacionais eram determinados pela expansão do capital, no caso, especificamente orientado pelo desenvolvimento das forças produtivas e nos mecanismos de extração da mais-valia.

Para Machado (1989), o aperfeiçoamento técnico da mão de obra, ou no caso deste estudo, a Pedagogia Industrial, eram sinônimos de maior quantidade de mais-valia, sem que necessariamente seja preciso intensificar o processo de trabalho. 
Porém, mais do que competência técnica, o alvo deste novo quadro pós 1964, era a busca pelo controle ideológico: daí a ênfase no disciplinamento, no hábito, no comportamento do trabalhador, por meio de processos educativos. Tudo isso visando a estabilidade política, que era essencial para a entrada dos investimentos estrangeiros no Brasil. "O Instituto de Desenvolvimento Industrial de Minas Gerais (INDI), por exemplo, publicou um folheto intitulado Introductionto Minas Gerais, como propagando junto a firmas estrangeiras, com o objetivo de atraí-las para este estado." (MACHADO, 1989, p. 66, grifos da autora).

E o ano de 1965, por seu turno, teve como destaque a constituição da EPEM (Equipe de Planejamento do Ensino Médio), que no que diz respeito ao ensino profissional, retomou a tentativa de aperfeiçoar os ginásios orientados para o trabalho, acompanhando e avaliando as experiências que deles se originavam.

Eram claras a influência e a participação norte-americanas neste programa, para o qual foi assinado um convênio do Ministério da Educação com a Agência Norte Americana para o Desenvolvimento Internacional (USAID), que definia, inclusive, a participação direta de técnicos daquela nacionalidade. A equipe era composta de, no mínimo, quatro técnicos brasileiros e de quatro assessores norte-americanos, aos quase foi atribuído o papel de consultores. Estes foram escolhidos pela San Diego StateCollege Foundation e pagos pela USAID. Além desse convênio, foram firmados outros complementares, com o Conselho de Cooperação Técnica da Aliança para o Progresso (CONTAP). (MACHADO, 1989, p. 52)

Nessa mesma perspectiva, foi observado que a FIEMG também manteve vínculos os Estados Unidos, assim como mostraram as fontes.

O objetivo do MEC, em 1965 era ampliar a matrícula em cursos técnicos sob a justificativa que "[...] as indústrias buscam os técnicos e não os estudantes de ginásio." (MACHADO, 1989, p. 53).

Porem, com a emergência das lutas sociais, o Estado foi pressionado a alterar essa estrutura do ensino. E além disso, a própria burguesia industrial, em detrimento da sua incapacidade de substituir sozinha o poder das oligarquias rurais e em busca do apoio das massas, propôs um amplo programa de expansão industrial, no qual se destacavam, para os trabalhadores, perspectivas de emprego e de elevação do nível de vida (MACHADO, 1989). Foi assim que começaram a concretizar algumas conquistas no âmbito educacional formal - ainda que na prática, as relações sociais de produção continuavam afirmando a reprodução da desigualdade.

\section{Considerações Finais}

A formação profissional a favor do capital corresponde, a partir do debate aqui estabelecido, à constituição da Pedagogia Industrial concretamente identificada na Revista Vida Industrial. A qualificação da grande massa que compunha o operariado industrial e também dos que estavam à frente do processo produtivo, destinou-se ao adestramento para o trabalho.

A Pedagogia Industrial, sob essa lógica do capital e da indústria, correspondia então à qualificação profissional enquanto sinônimo da mercantilização ocorrida nas relações entre trabalho e educação. Foram essas as diretrizes que desembocaram numa 
gama de transformações tanto na organização da produção, quanto no trabalho a ela inerente.

A Pedagogia Industrial, portanto, veio alimentar as contraditórias necessidades do capital, que concomitantemente exercia o controle do saber operário negando-o e afirmando-o, por meio de critérios de valorização e desvalorização do saber teórico e do saber prático.

Tratou-se de uma série de estratégias, preocupações e tentativas de adequar/adaptar o sistema educacional às necessidades da expansão capitalista. Contudo, é complexo garantir essa correspondência entre essas duas dimensões e é justamente por isso que o Estado e a indústria também intervinham na escola e nos órgãos representativos da educação.

Então, foram inúmeras as vantagens oriundas da participação direta das indústrias na formação de trabalhadores: a indústria podia influenciar na seleção, formação e preparo dos trabalhadores, para que pudesse recebê-los ajustados a seus objetivos e necessidades; aos trabalhadores foram propiciadas situações reais de trabalho e contato com novas máquinas e equipamentos; além disso, estes trabalhadores passaram a conhecer as reais dificuldades do ambiente de trabalho e tiveram contato com a concretude do sistema produtivo em suas demandas cotidianas.

Porém, por outro lado, o debate, problematização e compreensão do trabalho enquanto processo educativo sob a perspectiva do materialismo histórico dialético também norteia as orientações e formas de como superar as relações capitalistas de produção de modo que o trabalhador saiba se organizar e resistir à exploração rumo à acumulação do capital, objetivando o favorecimento do surgimento de novas formas de organização do trabalho.

A partir dessa discussão, fica perceptível que a educação é um instrumento essencial de formação dos indivíduos. Tanto que por de trás de um discurso ideológico e tendencioso próprio da sociedade de classes, a formação dos trabalhadores da indústria, nos moldes do imperativo do Estado a serviço do mercado, revela a sua mais perversa face: mera falácia.

Portanto, por outro lado, uma nova organização do trabalho requer, consequentemente, uma nova concepção de trabalho - uma mudança tanto no âmbito da infraestrutura (nas relações sociais de produção e nas forças produtivas que expressam a organização do processo de trabalho) quanto no da superestrutura (visando superar o trabalho alienado). Trata-se da retomada da pedagogia do trabalho em contraposição a Pedagogia Industrial: é na Pedagogia Industrial que estão os germes para desenvolver-se a pedagogia do trabalho - uma articulação dialética entre o velho e entre o novo.

\section{Referências}

ALMEIDA FILHO, Niemeyer. Os limites estruturais da política econômica brasileira nos anos 80/90. 1994. s/f. Tese (Doutorado em Economia)-Instituto de Economia, Programa de Pós-Graduação em Economia, Universidade Estadual de Campinas, Campinas-SP, 1994.

KUENZER, Acácia Zeneida. Pedagogia da Fábrica: as relações de produção e a educação do trabalhador. São Paulo: Cortez: Autores Associados, 1989. 
MACHADO, Lucília R. de Souza. Politecnia, escola unitária e trabalho. São Paulo, Cortez, 1989.

MARTINS, Luciano. Industrialização, Burguesia Nacional e Desenvolvimento. Rio de Janeiro: Saga, 1968.

PRIORI, Angelo. A Doutrina de Segurança Nacional e o Manto dos Atos Institucionais durante a Ditadura Militar Brasileira. In: Revista Espaço Acadêmico. N ${ }^{\circ}$ 53, abril, 2004. Disponível em: http://www.espacoacademico.com.br/035/35priori.htm Acesso em: 18 jul. 2013.

REVISTA VIDA INDUSTRIAL. Belo Horizonte: Federação das Indústrias do Estado de Minas Gerais, abril-julho, 1963, ANO X.

REVISTA VIDA INDUSTRIAL. Belo Horizonte: Federação das Indústrias do Estado de Minas Gerais, janeiro-fevereiro, 1964, ANO XI.

REVISTA VIDA INDUSTRIAL. Belo Horizonte: Federação das Indústrias do Estado de Minas Gerais, maio-junho, 1964, ANO XI.

REVISTA VIDA INDUSTRIAL. Belo Horizonte: Federação das Indústrias do Estado de Minas Gerais, setembro-outubro, 1964, ANO XI.

REVISTA VIDA INDUSTRIAL. Belo Horizonte: Federação das Indústrias do Estado de Minas Gerais, novembro-dezembro, 1964, ANO XI.

SINGER, Paul. A Economia Brasileira depois de 1964. In: A Crise do "Milagre". Editora Paz e Terra, Rio de Janeiro, 1976, p. 77-101.

Notas

${ }^{1}$ Doutora em Educação - Universidade Federal de Uberlândia e Faculdade Politécnica de Uberlândia: jane05@uol.com.br

${ }^{2}$ Doutorando em Educação - Universidade Federal de Uberlândia: cinvalfilho@yahoo.com.br

${ }^{3}$ A Pedagogia Industrial, para Kuenzer (1989), se define como ajustamento dos trabalhadores às normas e formas de trabalho às quais eles são submetidos. Essa ajustamento se faz presente nos diferentes modos de organização da produção, ainda que se utilize da captação da subjetividade dos trabalhadores para que a face exploratória e precarizada do trabalho se tornem ainda mais oculta e complexa. Trata-se de formar um tipo de trabalhador, adaptado e/ou adaptável à falácia dos conteúdos de aprendizagem, delineados pelo empresariado industrial nos mais diversos setores produtivos.

Recebido em Janeiro/2014

Aprovado em Março/2014 